\title{
Public health experts are learning from Canada's anti-mask protests
}

\author{
n Cite as: CMAJ 2020 October 19;192:E1274-5. doi: 10.1503/cmaj.1095901
}

Posted on cmajnews.com on October 1, 2020

$\mathrm{T}$ he first effective vaccines against severe acute respiratory syndrome coronavirus 2 (SARSCoV-2) will likely become available within the next year, but their impact on global health will depend on public acceptance and uptake. Winning that trust won't be easy if recent protests over face coverings are any indication. However, health experts are drawing important lessons from the anti-mask movement, too.

According to Alison Thompson, a bioethics professor at the University of Toronto, the opposition to masks speaks to an underlying mistrust of public health messaging and the science around coronavirus disease 2019 (COVID19). "If we take [the backlash] as baseline data around how much mistrust is out there, we have reason to be concerned about how a vaccine will be taken up by the public," Thompson says.

\section{Trust is fragile}

Canadians' trust in government, doctors and scientists increased in the first months of the pandemic, and early adopters of masks spanned the political spectrum. However, that cross-partisan consensus splintered as the pandemic wore on. By early June, $94 \%$ of left-wing Canadians reported wearing masks as part of their normal routine compared to $68 \%$ of those who identified as rightwing, and the divide between the groups appears to be increasing.

Conservatives are also more likely to endorse conspiracy theories about COVID$19-\mathrm{a}$ trend that may have less to do with politics than trust in media, which has decreased across the board during the pandemic. As of July, almost 1 in 10 Canadians in a nationally representative sur-

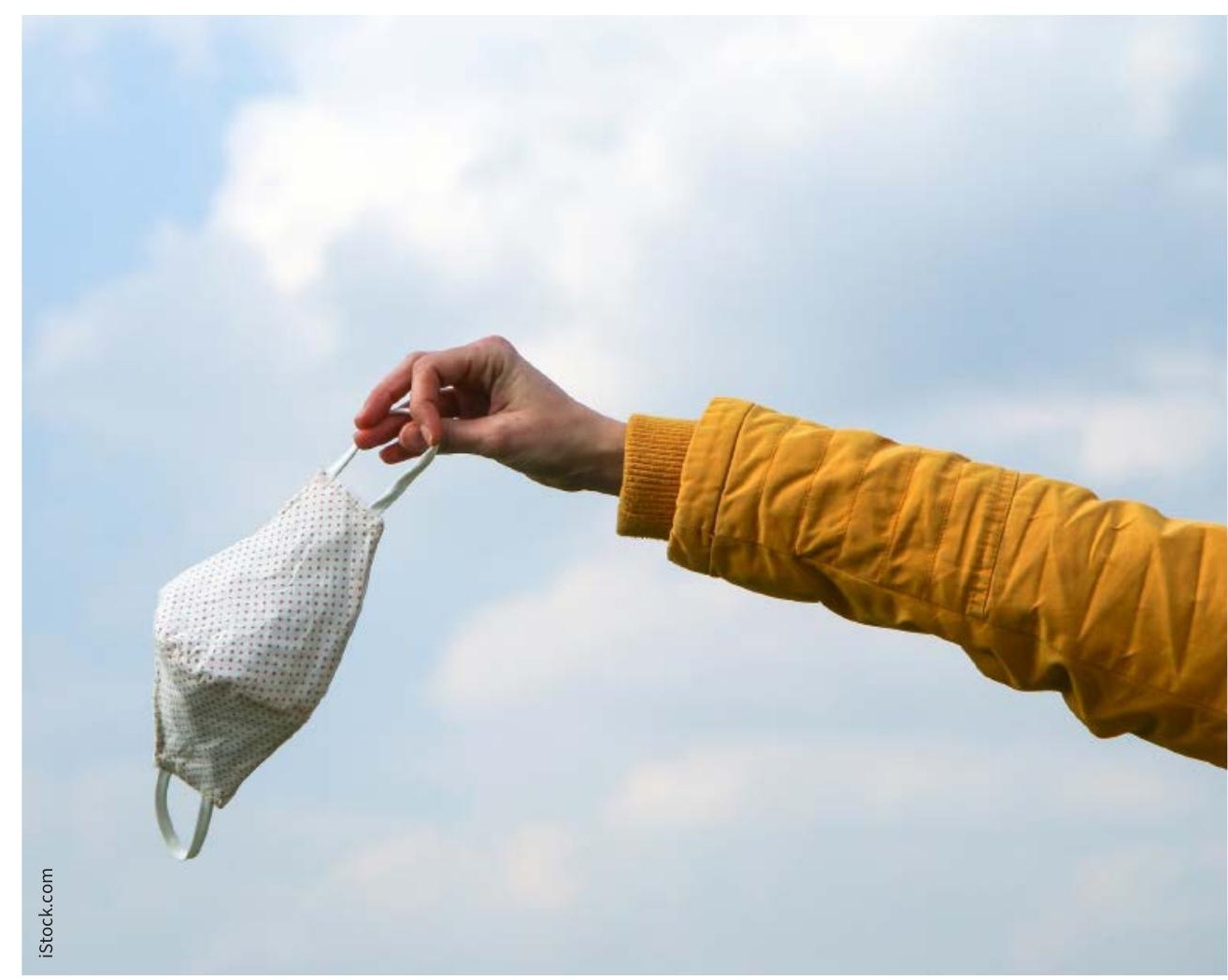

The backlash against wearing masks is a cautionary tale about mistrust and miscommunication.

vey believed Bill Gates is using the pandemic to push a vaccine with a microchip capable of tracking people. The same survey linked fringe beliefs to lower compliance with public health precautions. Notably, the backdrop for speakers at one recent anti-mask rally in Montreal included a flag for QAnon - a far-right movement centred around a theory that United States President Donald Trump is waging a secret war against a global cabal of pedophiles.

Conspiracy theories aside, overcoming skepticism about the safety of a SARSCoV-2 vaccine will be challenging given the unusual speed of development, the use of hitherto-untried technologies, and ever-changing predictions about availability. "We have a lot of work to do in demonstrating that we have taken all the precautions necessary and that [a vaccine] isn't being rushed to market prematurely," Thompson says.

Another lesson from the anti-mask movement is the significance of personal choice at a time when other freedoms are curtailed. Although governments have yet to decide whether to mandate vaccination against SARS-CoV-2, it will be important to "try to understand what the public considers acceptable," says Dr. Monika Naus, medical director at the British Columbia Centre for Disease Control. 
Show your work

A recent survey showed that one-third of Canadians would not choose to get the vaccine right away, largely because of fears about possible adverse effects. According to Dr. Sajjad Fazel, a public health researcher at the University of Calgary, such reluctance underlines the importance of improving public knowledge about vaccines.

Fazel says sharing information about "how vaccines are developed, the different stages and phases that a vaccine goes through, and how safety and efficacy are determined" could build trust and acceptance of future vaccines.

Transparency is the best policy, Fazel says. He argues that people are "more open and understanding" when health experts aren't afraid to admit the limits of what they know.

By contrast, contradictory messages early in the pandemic about who should wear masks have contributed to ongoing confusion and distrust.

"We have to be very careful around messaging for the COVID-19 vaccine," says Dr. Kumanan Wilson, a clinician and senior scientist at the Ottawa Hospital Research Institute. Acceptance will hinge not only on the evidence, but also on how that information is shared with the public.

Wilson notes that the pandemic may be an opportunity to strengthen Canadian immunization policy more broadly. For example, "something that is lacking a bit right now is well thought-out informed consent," he says.

A recent "ethics check-up" of schoolbased immunization programs found that vaccine information given to parents and students varies across Canada. "For those seeking to make an informed decision, this can be confusing, if not off-putting," the authors wrote.
As with masks, communication about the risks and benefits of an eventual vaccine will need to be ongoing, Wilson says. And given heightened safety concerns, "we have to have good data tracking systems so that we can, on an ongoing basis, evaluate the effectiveness and the safety of the vaccine."

Another pillar of accountability might be establishing a vaccine injury compensation program to ensure easy recourse in the unlikely event of harm. "This [could be] part of our social contract with the public," Wilson says. Such compensation programs already exist in several countries and Quebec.

"We're going to have to rely on the public to go out and get this vaccine, so we need to make sure they are on board," Wilson says.

Sandani Hapuhennedige, Toronto, Ont. 